\title{
Enterocolitis necrótica y sífilis congénita en un recién nacido
}

\author{
Katherine Rossel C.'; Andrés Maturana P. 1; Marcela Pérez R. ${ }^{2}$; \\ María Teresa Vial P..$^{*}$ : Aníbal Espinoza G. ${ }^{4}$
}

\begin{abstract}
Resumen
Un recién nacido por cesórec a las 30 semanos de edad geslacional thijo de uno porejo promiscua cuya madre ro curpliś conscles prenádesi evalutionó con hipoglicemia, hiperbilirubinerria y distensión abdominol pragrasiva: -itulcs de VDRL en sangre del ccrdón umbilisal de $1 / 128$. FTA-A3S, hemoaglutinación y ElISA IgM paro reoonemcs rositrvos. Las imágenes de ultrosoncgratia y radiolocia mosiraban gas en lo via biliar y neumalosis intestinal. Los culivos bacerianos dieron rejultodos regalivos. En lo laparotomía se enconircion extensos signos de enteritis r.ecróica. Folleció al tercer dia ce vida en falla circulatoric. En la necropsia se enconraron alteraciones histológicas coraclerísicas ce s:fi.is en los tejóos sumorar ireumonia aloa', pancreórico e inteslinal, junto con extenso neumatcsis que alecioba todo ol irtestino delgado, el colon y el rec c.
\end{abstract}

'Palabras clave: sifil's congérira, erteri’is, recrótica, neunata: 'i

\section{Congenital syphilis and necrotizing enterocolitis in a newborn infant}

The elinical featues of a 30 weeks geskational oge, $2100 \mathrm{~g}$ birh wight, $48 \mathrm{~cm}$ birth iergth newborn male intant born by cesarean section after on unstpervised piegnancy to a sexually promiscuous couple are described. His cl nical course was marked by hypoglycemia, iperbilirubinema, progressive abdomina distention, circulaton foilure and beeding from the gas rointestina tract, cirway and skin puricture sites. VDRL tilles from cord blood were 1/128. FTA. ABS, hemegluti-alion and IgM ELISA rests gave positive results, Blooc cultures were negrive Penicillin and a modified artific al milk formula $20 \mathrm{ml}$ oer $\mathrm{kg}$ body weighi) were started in the first 12 hou's of life. Abdominal symploms and s'ans, iogether with evidenze of gas in the v'trasongaraphic evaluetion of the biliary tracl ane of intestinel pneurratosis af $X$ ray excrinictions promped surgical abcomnol exploration which showed extensive necrotizing enterocolitis. Posirtortem histolcgic examination showed signs suggestirg treponemal disease in lung, pancreatic and intestinch tissue and clisc generalized priesmarosis alorg the whole small bowell, colon and reclum.

iKey words enterocoluls, necrolizng. syph lis congenital.'

La sifilis congenita era considerada la primera causa de abortos y mortinatos antes de la introducción de los antibióticos. El descubrimiento de la penicilina produjo un importante

1. Unidad de Neonatología. Hospital Clínico San BorjaArriarán.

2. Departanento de Pediatria, Hospital Clínico San BorjaAmiarán.

3. Servicio de Anatomía Patológica, Hospital Clínico San Borja-Arriarón.

4. Servicio de Radjología. Hospital Clínico San BorjaArriarín descenso de casos hasta la década de 1980. La prostitución. el abuso de drogas ilícitas (cocaína) y la infección por el virus de la inmunodeficiencia humana han favorecido el posterior resurgimiento de esta enfermedad ${ }^{1 \cdot 3}$.

En Chile, donde son obligatorias las pruebas VDRL durante el embarazo en la madre $y$ en sangre de cordón al nacer, como parte de la vigilancia epidemiológica ${ }^{4}$, la incidencia de la enfermedad ha aumentado progresivamente y se ha mantenido la misma tasa de mortalidad $(0,08$ casos por 100.000 nacidos vívos) $)^{5}$ de manera semejante a lo sucedido en otros países ${ }^{1,6}$. 
Las manifestaciones clásicas de la sifilis congénita han sido ampliamente descritas ${ }^{1,2,6-9}$, pero su patrón clínico puede variar ${ }^{8}$, si la infección neonatal se pesquisa precozmente, antes de las secuelas, como es el caso del daño pulmonar agudo conocido como neumonía alba ${ }^{6}$. Hasta la fecha no ha sido descrito en recién nacidos, salvo en autopsias, el compromiso intestinal agudo producido por la espiroqueta. Por esta razón se presenta un caso de enterocolitis necrótica masiva, como posible expresión clínjca inusual de la sífilis congénita reciente.

\section{Caso Clínico}

Varón nacido por cesárea a las 36 semanas de edad gestacional, peso al nacer $2100 \mathrm{~g}$, talls $48 \mathrm{~cm}$, apgar 8 y 9 uno y cínco minutos después de nacer. Madre de 34 allos, inulípara, antecedentes de dos cesareas previas. condilomatosis vulvovaginal, Embarazo no controlado. Pareja sexual inestable y promiscua. El recien nacido presentó quejido a la hora de vida con requirimiento de oxigeno inferior a $40 \%$, dificulıad en la termorregulación e nipoglıcemia. Tenía una masa abdorninal palpable en flan. co izquierdo, fija, indolora y sin dilatación de asas. VDRL de cordón 1/128. Tratado con solución de giucosa endovenosa, corrigiéndose rápidamente la glicemia. Se inició alimentación enteral a las 12 horas de vida, con fórmula artificial(Pre-Nan(S) al 16.5\%) $20 \mathrm{ml} \cdot \mathrm{kg}$ - dia. En las primeras 24 horas de vida cursó con distensión abdominal progresiva, residuo gástrico bilioso, deposiciones acolicas, hipoglicemia persistente $\left(.32 \mathrm{mg}^{*} \%\right.$ ) y sangramiento en sitios. de punción vasculat y lumbar. La ultrasonografía abdominal mostcaba gases en la vía biliar y la radiografín de abdomen simple exicnsas arreas de neumatosis. En la laparotomía se encontraron equímosis y neumatosis generalizada en inlestino delgado y grueso, sin perforación. Por 1a extensión del daño intestinal se efectuó únicamente ileostomía. Tratado con ventilación mecánica. catêter venoso central y arterial, amikacina, penicilina, metronidazol, dopamina, dobutamina y transfusiones de plasma, glóbulos rojos y plaquetas, evolucionó con signos de choque séptico (falla circulatoria y renal. hemortagia pulnonar y digestiva) y convulsiones iterativas que respondieron a fenobarbital endovenoso. Los bemocultivos fueron negativos. Las pruebas de anticuerpos treponémicos fluorescentes (FTA Abs), hemaglutinación y Elisa IgM para la confirmación etiológica de sífilis fueron positivas en sangre. En el líquido cefalorraquídeo no se elecluó estudio, debido a la contaminación con sangre durante la punción lumbar. Falleció a la edad de tres y medio días en falla circulatoria.

En la necropsia se encontró engrosamiento y opacidad de las meninges sin signos macroscópicos de encefalitis, infartos o hemorragia, hepatomegalia, esplenomegalia y extensas hemorragias pulmonares, necrosis y focos hemorágicos en todo el tracto digestivo, neumatosis genemalizała -sin perforación- en todo el intestino delgado, colon y recto. En el exaınen microscópico de los pulmones se registró engrosamiento intersticial, fubrosis incipiente e infiltrado inflamatorio linfoplasmocitario y signos facales de inmadurez (figura l). En el hígado se observó acentuada atrofia trabecular, fibrosis intersticial y portal. Habia signos de pancreatitis crónica intersticial difusa con fibrosis y acentuada atrofia parenquimatosa de la glándula (figura 2). En el intestino se enconiro engrosamiento y fibrosis de la submucosa iniestinal, infittrado mononuclear linfoplas. mocitario y leucocilos polimorfonucleares en áreas de necrosis a nivel de la mucosa (figura 3). Los riñones mostraban signos histológicos de retardo en la maduración correspondiendo esta a 56 lo 30 semanas de gestación. La tincion de Warthin Starry no permitjó detectar espiroquetas en los tejidos.

\section{Comentario}

El contagio venéreo de la sífilis se ha asociado a numerosos factores de riesgo, sin embargo únicamente la falta de control prenatal ha demostrado tener una estrecha cortelación $(70 \%$ a $86 \%$ ) con el riesgo de adquirir sifilis congénita ${ }^{1-3}$. El diagnóstico es básicamente serológico, dada la extrema fragilidad de la espiroqueta y lo costosa de las técnicas histoquímicas? 9. 1i. 12 Las pruebas no treponémicas (RPR, VDRL) se emplean como pruebas de rastreo y las treponémicas (MHA, FTA-ABS, Elisa IgM), caras pero más específicas y sensibles para confirmar la infecciónn 1. 7-9. 13. La mancha de Western, la reacción de polimerasa en cadena, son métodos nuevos, dan certeza, pero su gran coste limita su empleo ${ }^{13,17}$.

En el caso que se comenta, el diagnóstico de sífilis está bien documentado por los antecedentes clínicos y resultados serológicos de rastreo y confirmación.

Cuando el Treponema pallidum infecta a la madre, produce una pequeña bacteremia desde el sitio de inoculación, pero no invade al feto sino dos a tres semanas después, cuando la concentración de espiroquetas en la sangre es mayor. Estos agentes pueden ser aislados de placenta y el cordón umbilical aun antes de detectarse respuesta inmunitaria en la madre, рог lo que algunos clínicos y patólogos sugerieren, en embarazos no controlados y madres seronegativas, intentarlo en el parto, o bien repetir el VDRL tres a seis meses después en la madre y el niño ${ }^{15}$. La espiroqueta puede atravesar la placenta en cualquier etapa del embarazo. Antes de las 24 semanas de gestación el feto es muy tolerante a la bacteria y no se produce gran daño 


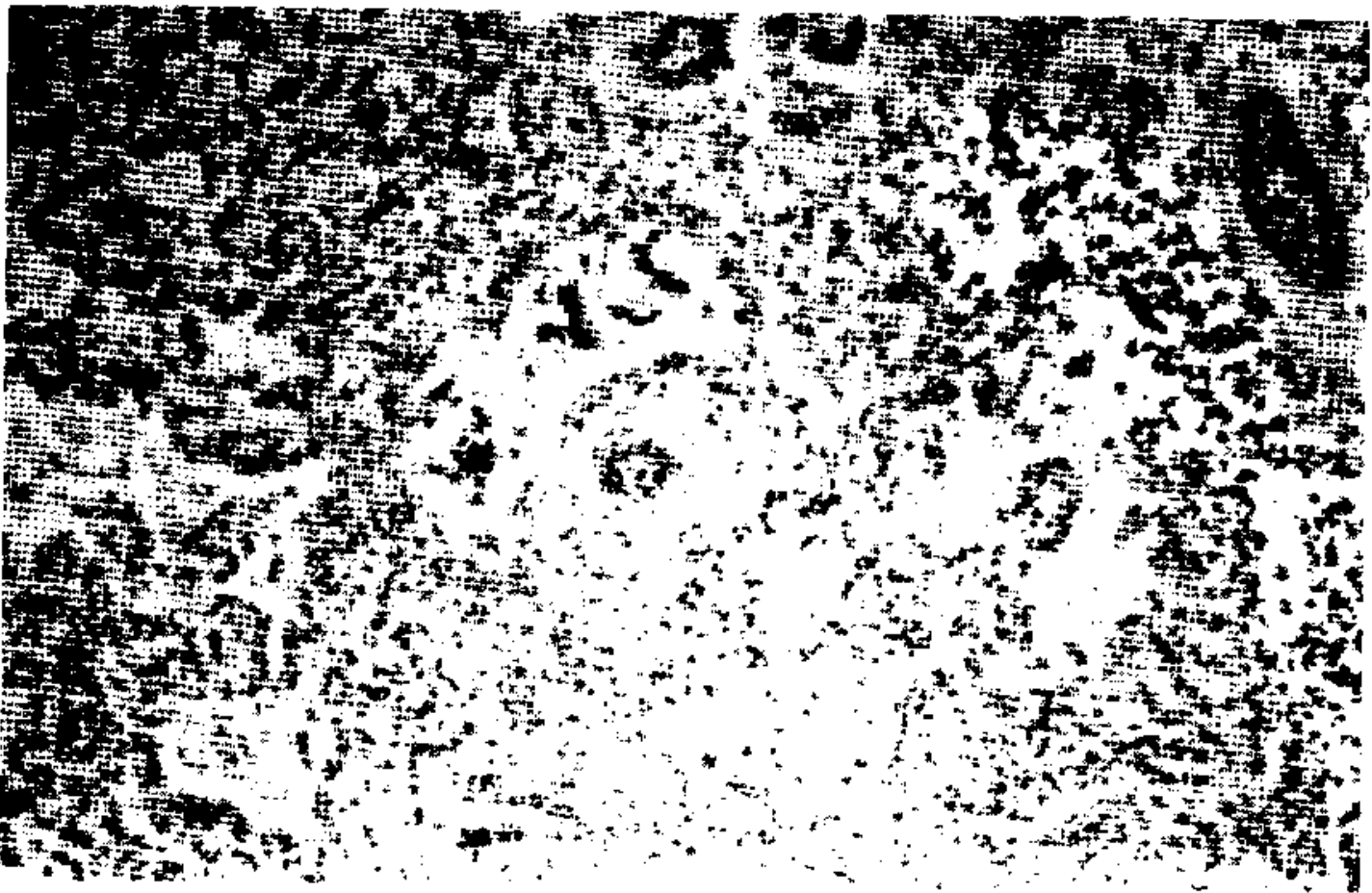

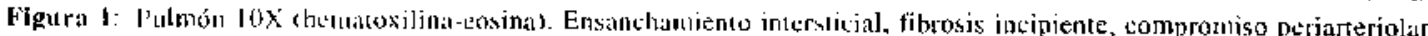
e infiltrado inllamiturio montnutear.

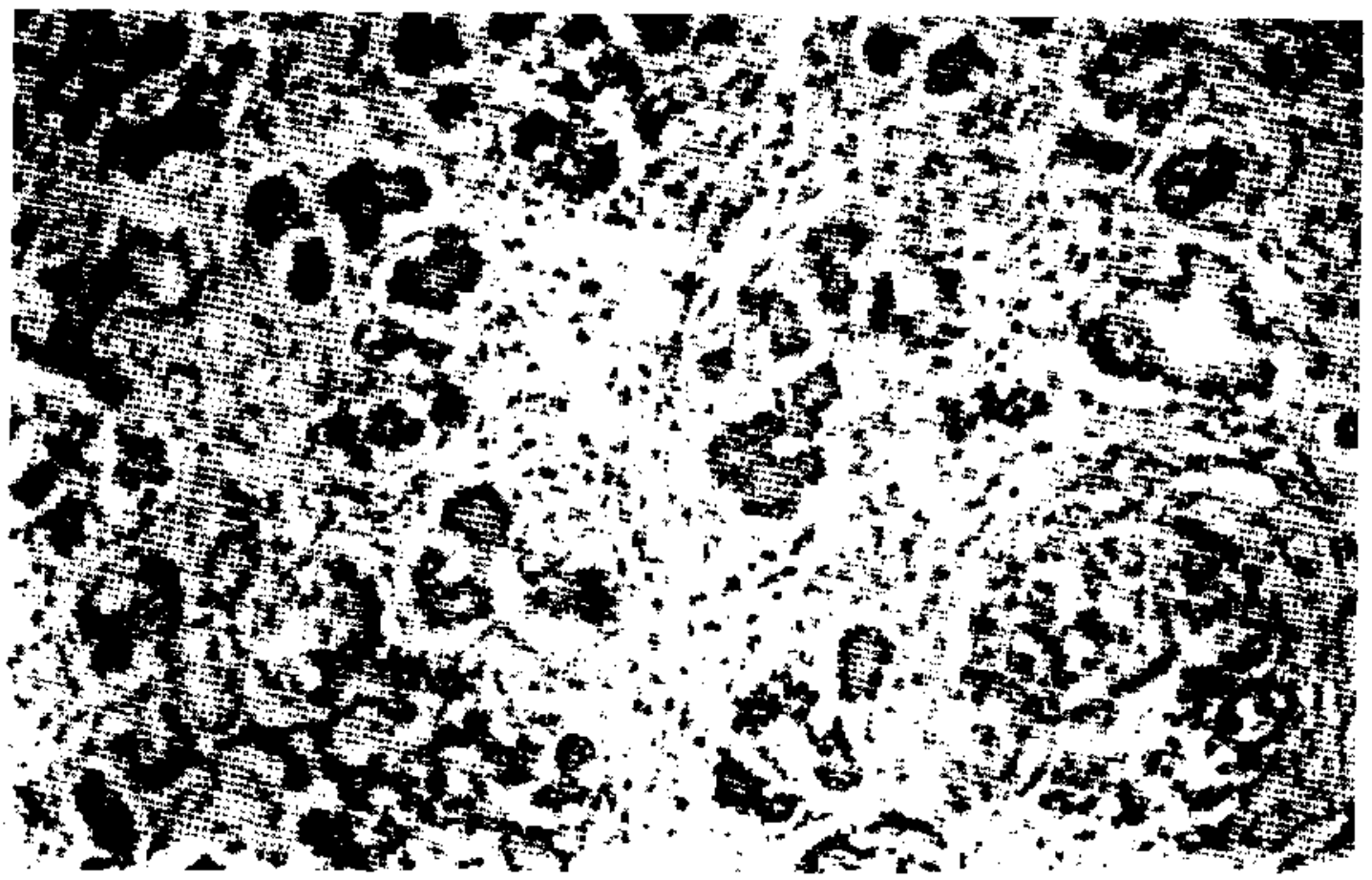

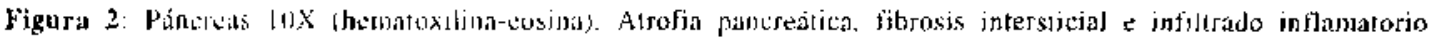
thononiclinr. 


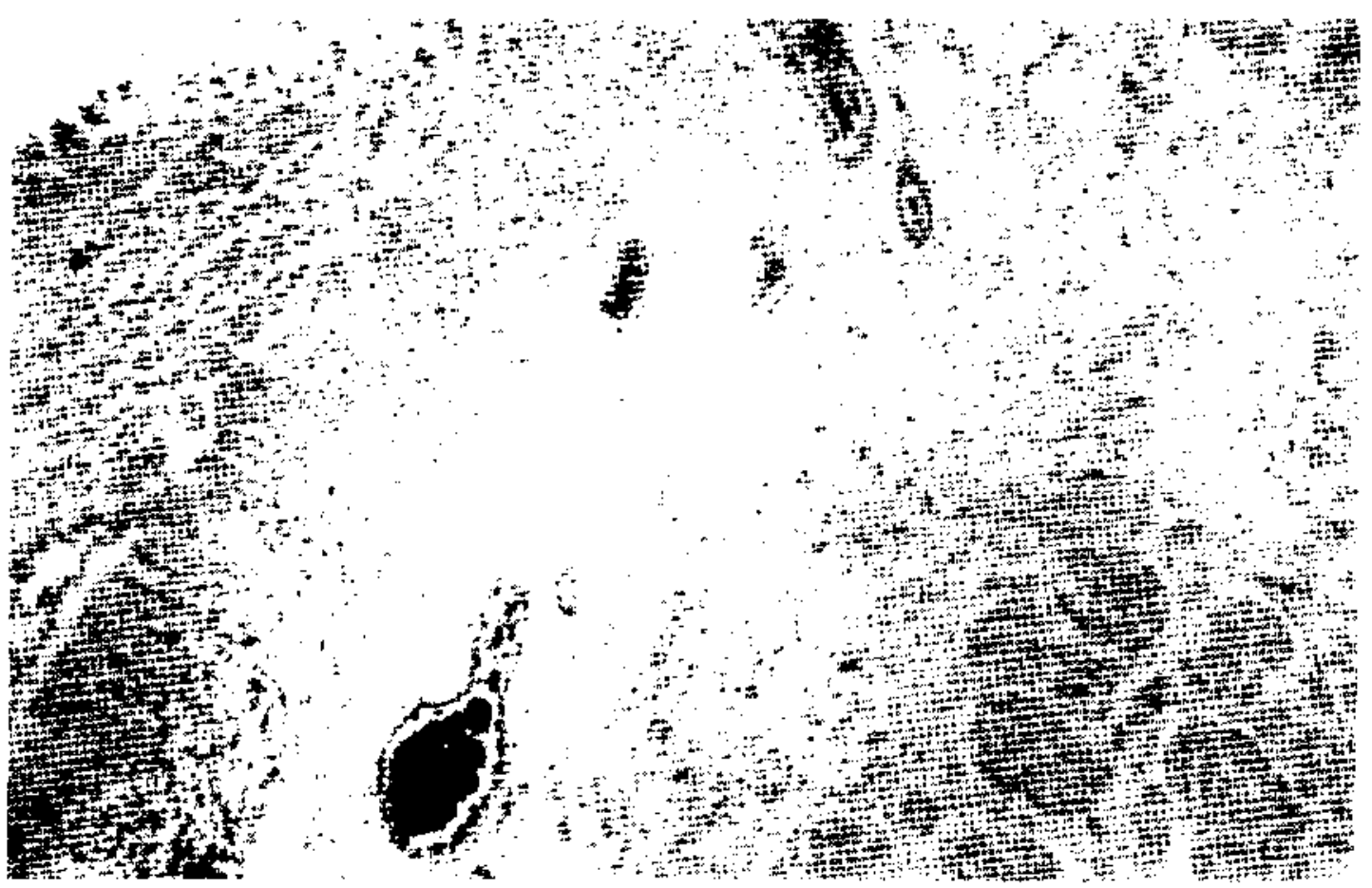

Figura 3: Intcstino loX (hematoxilina-eosina). Fibrosis incipiente de la submucosa e infiltrado linfoplasmocitario.

en él, dada la inmadurez de su sistema inmunitario. Euego el treponema causa mortinatos, partos prematuros y neonatos enfermos ${ }^{1.7-9}$. La reaccion inmunitaria desencadenada por el treponema es generalizada y se caracteriza por infiltrado perivascular, preferentemente mononuclcar, el cual comprime la luz arteriolar, reduce cl 1lujo sanguineo, desencadenando posteriormente isquemia y necrosis focal ${ }^{7} 8$. En el paciente descrito se cumplió lo citado por Oppenheimer y Dahm ${ }^{\&}$, encontraron alteraciones características y específicas en pulmon. páncreas e intestino. El engrosamiento del intersticio pulmonar con fibrosis e infiltrado mononuclear linfoplasmocitario, corresponden a lo descrito cono neumonia alba y son muy sugerentes de sífilis congénita, explicando la polipnea y el temprano aumento de la demanda por oxígeno. La pancreatitis intersticial con fibrosis y atrofia a los tres dias de vida, señala una evolución crónica, probablemente secundaria a la infección intrauterina. El retardo focal de la maduración pulmonar no parece descrito en la litcratura $y$, junto a la inmadurez renal permiten estimar el contagio materno alrededor de las 27 semanas de gestación. La atrofia trabecular hepática y la fibrosis intersticial y portal no son, en este paciente, atribuibles a otro agente bacteriano. viral o parasitario. Pese al resultado negativo de la tinción de Warthin Starry, que podria deberse al tratamiento con penicilina, las alteraciones histopatológicas eran muy sugerentes de infección congénita por sífilis.

El engrosamiento y fibrosis de la submucosa intestinal, junto a la reacción inflamatoria caracterizada principalmente por mononucleares y células plasmáticas, no corresponden a lo esperado en la etapa aguda de una enterocolitis necrótica ${ }^{7-9}$ lo que hace suponer que antes del parto el Treponema pallidum lesionó el intestino, debilitó la barrera intestinal y favoreció la ulterjor puesta en marcha de mecanismos patogénicos que, incluida la invasión bacteriana, facilitaron la evolución hacia esta entidad.

El progreso en el diagnóstico y tratamiento precoz de la sífilis congénita son indiscutibles, pero el reciente y sostenido aumento de su incidencia hace necesario impulsar políticas más eficientes de protección y prevención contra la enfermedad. 


\section{Referencias}

1. Bewr MC. Dajomi AS: Resurgence of congenital syphilis. Infect Dis Clin North Am 1992: 6: 19-29.

2. Lis CC. So $W C$. Lin CH. Yeh TF: Congenital syphilis: Clinical inanifestations in premature infants. Scand J Infecl Dis 1993; 25: 741-745.

3. Webler MP. Lasmbert G. Bareman DA. Hauser WA: Maternal risk iactors for congenital syphilis: A case control study. An J Epidenol 1993: 137: 415-422.

4. Ansinima: Normas nacionales para el control de las enfermedades venéréas. Ministerio de Salud Pública. Sautiago de Chile, 1976.

5. Anónimo: Anuarios demográficos de egresos hospitalarios. Institulo Nacional de Esıadisticas. Ministerio de Salud. Chile, Santiago de Chile, 1987-93.

6. Edell DS. Dusisen JJ. Mutrihill DM. Majme M: A comnon presentation of all uncommon cauke of neonatal respiratory distress: pneunonia alba. Pediatr Pulınonol 1993: 15: 376-379.

7. Singer $D B$ : Intectious diseases of fetus and geonates. En: Wigglesworth J, Singer D. ed. Textbook of tetal and perinatal pathology. Blackwell scientific $\mathrm{Pu}$ blication, Boston 1991: 525-591.

8. Oppenheiner $E H$. Dahms $8 B$ : Infestions in fetus and neonates. In: Rosemberes S. Berstein J. ed. Perspective in pediatric pathology. Editorial Masson Publishing Chicago, 1981; 115-138

9. Suncison J. Lichetenbery F: In: Cotran R, Kumar V. Robbins $S$. ed. Infections disease. Pathology basics of disease. Editorial WS Saunders Company. 5th Edition, Philadelphia 1994; 305-378.

10. Juez $G$, Lucero E, Ventara-Juncú $P$ : Crecimiento intrauterino en recićn nacidos ehilenos de clase media. Rev Chil Pediatr 1989; 60: 198-202.

11. Lewis $L L$ : Congenital syphilis. Serologic diagnosis in the young infant. Infect Dis Clin North A In 1992; 6: 31-39.

12. Sihwert: DA, Larsen SA, Beck Sague $C$, Fears $M$, Rice RJ: Pathology of the umbilical cord in congenital sy-philis. Analysis of a 25 specimens using histochemestry and inmunofluorescent antibody 10 Treponema pallidum. Hum Pathol 1995; 26: 784-791.

13. Jonna S. Collins M. Abedein M. Yowny M. Milteer R: Postneonatal screcuing for congenital syphilis. J Fam Pracl 1995: 41: 286-288.

14. Meye MP. Eddy $T$, Buaghn $R E$ : Analysis of westem blotting (immunobloting) technique in diagnosis of congenitol syphilis. I Clin Microbiol 1994; 32 : 629-633

15. Chong SN. CJung $K Y$, Lee MG, LEe JB: Seroreversion of the serological test for syphilis in the newborn born to treated syphilitic mother. Genitourin Med 1995: 71 : 68.70. 